\title{
Judgments of Social Justice: Compromises Between Equality and Efficiency
}

\author{
Gregory Mitchell, Philip E. Tetlock, Barbara A. Mellers, and Lisa D. Ordóñez
}

\begin{abstract}
Political economists agree that a trade-off exists between equality and efficiency. Using a hypothetical society paradigm, we manipulated the mean income (representing efficiency) and income variability (representing equality) of distributions of wealth and the correlation between wealth and effort within a society. Subjects made all pairwise comparisons of distributions within societies of differing meritocracy. A "maximin" principle best described trade-off resolution strategies when effort and outcome were weakly linked: People maximized the minimum standard of living within a society. A compromise principle best described preferences when income was tightly linked to effort: People rejected distributions in which some citizens fell below the "poverty line" but maximized efficiency above this constraint. Ideological polarization was pronounced under moderate meritocracy; here liberals could focus on the role of chance and conservatives on the role of effort and ability.
\end{abstract}

A central tension in theories of distributive justice is the trade-off between equality of wealth distribution and efficiency of wealth generation (see Bowie, 1971; McConnell, 1987; Okun, 1975). On the one hand, to promote social equality, most political economists deem it necessary to provide compensatory welfare programs favoring the disadvantaged and funded by the advantaged. These egalitarian measures create economic inefficiencies because the redistribution process inevitably involves "leakage" caused by human error, fraud, and the complex bureaucratic agencies required to implement social programs. In addition, funds are diverted from entrepreneurial activity, and disincentives to provide for oneself are produced. On the other hand, to promote efficiency, most political economists deem it necessary to reduce regulation and taxation to permit capital to flow freely into the most productive investments. Reduced government revenue and regulation generally translate into less welfare spending and less protection for those least equipped to fend for themselves in a free-market society.

Social scientists disagree over the functional form of the equality-efficiency trade-off. It is unclear how much efficiency is lost for any given increment in equality (cf. Bauer, 1981; Davis \& Moore, 1945; Friedman, 1962; Kuttner, 1984; Okun, 1975; Thurow, 1980). There is wide agreement however, among both political economists and ordinary people, that equality and efficiency are often in conflict with each other (see Cook \& Pearlman, 1981; Dahrendorf, 1988; Hochschild, 1981; Verba \& Orren, 1985; but also see Deutsch, 1989, for a dissenting voice).

Gregory Mitchell, Philip E. Tetlock, Barbara A. Mellers, and Lisa D. Ordóñez, Department of Psychology, University of California, Berkeley.

Many thanks to Linda Skitka at Southern Illinois University at Edwardsville for help with data collection. Thanks also to reviewers of this article, several of whose suggestions were incorporated.

Correspondence concerning this article should be addressed to Gregory Mitchell, Department of Psychology, Tolman Hall, University of California, Berkeley, California 94702.

\section{Possible Resolutions of the Trade-Offs}

Equality-efficiency trade-offs have important psychological implications. People confront a painful choice: How much inequality or inefficiency are they willing to tolerate? We identify three broad perspectives on people's preferences for equality and efficiency. 1

\section{Value-Guided Perspective}

One possibility is that in the course of socialization, people acquire relatively stable preferences for equality and efficiency that serve cognitive appraisal functions. Equality is an important organizing principle in liberal and social democratic ideology, as are efficiency and economic liberty in conservative and laissez-faire ideology (McClosky \& Zaller, 1984). Thus, liberals may use the impact of government action on equality as a cue for whether they should support or oppose particular policies and likewise for conservatives and efficiency cues. Accordingly, Rohrbaugh, McClelland, and Quinn (1980) found that conservatives emphasized overall utility (the efficiency of collective outcomes) in judging the "favorableness" of different labormanagement contracts, whereas liberals emphasized equality (minimizing the difference between outcomes of parties) in their favorableness ratings. Rasinski (1987) reported that people valuing egalitarianism, as opposed to proportionality (eq-

\footnotetext{
'Actually, four general orientations can be identified. The fourth, a simple self-interest approach, maintains that people will advocate those government policies that they believe will most benefit themselves and their social group. The poor should favor greater regulation and greater equality; the wealthy should favor less interference in their financial affairs and less equality. Although direct links between immediate personal interests and policy preferences are tenuous, group interests are more predictive of policy preferences (see Sniderman \& Tetlock, 1986). The role of economic self-interest in deciding between equality and efficiency, although theoretically important, was diminished greatly in our research because we examined people's ideals about distributive justice free of material incentives.
} 
uity and economic individualism), believed that equality-based political policies are fairer than equity-based policies.

\section{Compromise Perspective}

Boulding (1962) offered a second perspective on the equality-efficiency problem. He argued that societies continually compromise between these two goals. To avoid alienating the disadvantaged, people favor redistribution to satisfy basic needs and provide opportunities to become self-reliant; beyond providing these basic programs, however, people desire a distribution of rewards that are based on merit. This analysis implies a dynamic tension between the goals of promoting productivity and equality. As Boulding (1962) put it,

\begin{abstract}
We face the dilemma . . that if everyone gets his deserts, some may be driven from the table; and if everyone comes to the table, some may not get their deserts. In practice, this seems to be resolved by the establishment of a social minimum as reflected, for instance, in the poor law, in social security, and in various welfare services. The principle of desert may come into play above this social minimum. That is to say, society lays a modest table at which all can sup and a high table at which the deserving can feast. (p. 83)
\end{abstract}

There is considerable empirical support for Boulding's (1962) propositions. Mellers (1982) found that subjects used a contextdependent merit rule to set "fair" salaries but that salary levels were constrained by a floor paralleling the stated poverty line. Frohlich, Oppenheimer, and Eavey (1987; see also Frohlich \& Oppenheimer, 1990) found that experimental groups allocated rewards according to a rule that maximized average income but that did not allow any group member to fall below a certain income level. Alves and Rossi (1978; see also Jasso \& Rossi, 1977) reported fairness ratings of the distribution of incomes of fictitious families that corresponded to Boulding's predictions (i.e., incomes were considered fair when earned or when above a welfare minimum). Interview data (Rainwater, 1974) and historical research (Moore, 1978) provide additional support for Boulding's hypotheses.

\section{Rawls's Maximin Principle}

A third perspective derives from Rawls's theory of social justice, which maintains that people in the primordial "original position". would choose to organize their society so as to maximize the incomes of the poorest citizens (the maximin principle; Rawls, 1971). In a widely cited thought experiment, Rawls argued that if people were placed behind a "veil of ignorance" so that no one knew of their future standing in society, then everyone would agree to maximize the standard of living of the least fortunate. People will converge on this maximin solution, according to Rawls, because they fear they may be assigned to the bottom of the social ladder and because it is rational (albeit highly risk averse) to maximize the resources one would have in the event one landed in this position (i.e., everyone tries to ensure themselves against the worst-case outcome). It is important to note that maximin subordinates the goals of both efficiency and absolute equality. Maximin precludes both increments in efficiency that benefit only the rich and increments in equality that enhance the relative but diminish the absolute standard of living of the poor.
Little empirical support for Rawls's (1971) theory of justice has been generated (cf. Curtis, 1979; Frohlich et al., 1987; but also see Brickman, 1977; Schulz \& May, 1989), but this is not surprising given that it is a purely normative theory that relies on intuitions about how people would act in the empirically unattainable original position. Even approximating the original position in the laboratory is not possible (although researchers have made ingenious attempts) because Rawls's veil of ignorance requires depriving people not only of knowledge of their position in society but also of knowledge about themselves: their intelligence, basic risk preferences, talents, and so forth (see Rawls, 1971, pp. 136-142). The lack of experimental support for maximin is thus not seriously damaging to Rawls's normative theory of justice (cf. Brickman, 1977).

\section{Comparing the Orientations}

None of the aforementioned research has specifically studied how people make trade-offs between equality and efficiency to reach judgments of justice. In this research we examine whether a compromise orientation as suggested by Boulding (1962), a maximin orientation derived from Rawls (1971), or a value-guided orientation would better describe how people resolve this trade-off. To compare these trade-off approaches, we had subjects judge the fairness of income distributions in hypothetical societies in which we experimentally eliminated any role of material self-interest and manipulated the degree to which values actually came into conflict. That is, we created alternative hypothetical societies with varying efficiency of wealth generation and equality of wealth distribution and required subjects to judge the relative fairness of the societies; we then compared the behavior of the subjects with the ideal pattern of behavior predicted by each orientation.

The ability to manipulate value conflict is especially important because of the well-documented tendency of people to avoid value trade-offs (Abelson \& Levi, 1985; Einhorn \& Hogarth, 1981; Festinger, 1957; Slovic, 1975; Tetlock \& McGuire, 1986). For a host of mutually reinforcing reasons-cognitive, emotional, and political-people do not like to acknowledge tension between cherished values and expend considerable effort to define situations so that a clear-cut dominant option emerges. In the present context, for example, egalitarians might argue that higher taxes to help the poor promote efficiency by expanding the productive labor pool, reducing crime, and so on. Alternatively, libertarians might argue that the best way to help the poor is to give free rein to market forces that will in turn lead to vigorous job creation and price competition. Our goal here was not to resolve these well-rehearsed arguments of political economy but to create an experimental paradigm that would allow us to observe the choices people make when their factual judgments about the impact of policies are not confounded with their value judgments about a just world.

The hypothetical society paradigm allowed us to achieve this goal. In the present case, we described a series of societies in which "econometric studies" had determined (beyond reasonable doubt) what effect various policies would have on the income distributions. Some policies emphasized efficiency (the overall standard of living); others emphasized equality (the difference in average income between classes). The task of subjects was to compare the income distributions that resulted from 
these policies and to decide which distributions would be best for the people of this society.

The income distributions used in Studies 1 and 3 are shown in Table 1. In comparing pairs of distributions, subjects had to choose between different levels of equality and efficiency as operationalized in terms of the income variability and average prosperity of the income distribution in this society, respectively. It should be noted that efficiency is defined here to be a move toward greater overall prosperity in society (i.e., a move toward Pareto optimality in that no individual's wealth decreases and at least one individual's wealth increases with such a move; see McConnell, 1987, chap. 38, on wealth maximization as one conception of efficiency; see also Dworkin, 1980; Hovenkamp, 1990a, 1990b; Posner, 1977, 1980).

Table 2 shows the predicted fairness rankings of societies ranging from 1 (least fair) to 9 (most fair) for the compromise, maximin, and value-guided perspectives. The compromise position predicts that subjects will least favor the three distributions ranked 2 because they allow some citizens to slip below the poverty line; above this floor constraint, the theory predicts that subjects will maximize efficiency. All of the distributions with high efficiency, ranked 8 , are higher than those with medium efficiency, ranked 5.5, or low efficiency, ranked 4 .

The maximin strategy entails a ranking of distributions according to income level of the lowest quarter. The society with the lowest average income in the bottom quarter is ranked 1, and the society with the highest average income in the bottom quarter is ranked 9.

The value-guided position predicts two rankings that are dependent on political orientation: (a) Egalitarians will maximize overall equality, such that high-equality distributions are of a higher rank than moderate-equality distributions, which are of a higher rank than low-equality distributions; (b) if utility is assumed to be equal to income, utilitarians will maximize effi-

Table 1

Income Distributions for Studies 1 and 3

\begin{tabular}{crrr}
\hline & \multicolumn{3}{c}{ Mean income (efficiency) } \\
\cline { 3 - 4 } $\begin{array}{c}\text { Income variability } \\
\text { (equality) by quarter }\end{array}$ & Low & Medium & High \\
\hline Low $^{\mathrm{a}}$ & & & \\
1 & 13,000 & 16,000 & 19,000 \\
2 & 23,000 & 26,000 & 29,000 \\
3 & 35,000 & 38,000 & 41,000 \\
4 & 75,000 & 78,000 & 81,000 \\
Medium $^{\mathrm{b}}$ & & & \\
1 & 9,000 & 12,000 & 15,000 \\
2 & 19,000 & 22,000 & 25,000 \\
3 & 39,000 & 42,000 & 45,000 \\
4 & 79,000 & 82,000 & 85,000 \\
High $^{\mathrm{c}}$ & & & \\
1 & 5,000 & 8,000 & 11,000 \\
2 & 15,000 & 18,000 & 21,000 \\
3 & 43,000 & 46,000 & 49,000 \\
4 & 83,000 & 86,000 & 89,000 \\
$M$ & 36,500 & 39,500 & 42,500 \\
\hline
\end{tabular}

Note. Numbers represent average income (in dollars) within a quarter.

${ }^{\mathrm{a}} \mathrm{SD}=27,197 . \quad{ }^{\text {b }} \mathrm{SD}=30,957 . \quad$ с $S D=34,924$.
Table 2

Predicted Rankings of Distributions

\begin{tabular}{|c|c|c|c|}
\hline \multirow{2}{*}{$\begin{array}{l}\text { Standard } \\
\text { deviation }\end{array}$} & \multicolumn{3}{|c|}{ Mean income } \\
\hline & Low & Medium & High \\
\hline \multicolumn{4}{|c|}{ Compromise theory } \\
\hline Low & 4 & 5.5 & 8 \\
\hline Medium & 2 & 5.5 & 8 \\
\hline High & 2 & 2 & 8 \\
\hline \multicolumn{4}{|c|}{ Maximum theory } \\
\hline Low & 6 & 8 & 9 \\
\hline Medium & 3 & 5 & 7 \\
\hline High & 1 & 2 & 4 \\
\hline \multicolumn{4}{|c|}{$\begin{array}{l}\text { Value-guided theory: } \\
\text { Egalitarianism }\end{array}$} \\
\hline Low & 8 & 8 & 8 \\
\hline Medium & 5 & 5 & 5 \\
\hline High & 2 & 2 & 2 \\
\hline \multicolumn{4}{|c|}{$\begin{array}{c}\text { Value-guided theory: } \\
\text { Utilitarianism }\end{array}$} \\
\hline Low & 2 & 5 & 8 \\
\hline Medium & 2 & 5 & 8 \\
\hline High & 2 & 5 & 8 \\
\hline
\end{tabular}

Note. A value of 1 represents the least preferred income distribution, and 9 represents the most preferred.

ciency, such that high-efficiency distributions are of a higher rank than moderate-efficiency distributions, which are of a higher rank than low-efficiency distributions.

Another version of the value-guided approach suggests that egalitarians and utilitarians use both equality and efficiency dimensions in a lexicographic fashion to conserve cognitive effort. For example, egalitarians might distinguish among societies with high equality on the basis of efficiency. Those with high efficiency would be ranked higher than would those with low efficiency. Thus, the first row in the predicted table for egalitarians would be 7,8 , and 9 rather than 8,8 , and 8 , and so on for the second and third rows.

\section{Possible Constraints on the Orientations}

The background against which people choose between equality and efficiency is potentially critical. Recall, for example, that Boulding's (1962) compromise theory assumes that merit is rewarded in a society. Just as people disagree about the exact functional form of the equality-efficiency trade-off, they also disagree over the extent to which rewards in the society are merit based and over how merit should be defined (Feagin, 1972; Feather, 1974, 1985; Kluegel \& Smith, 1981, 1986). Several theorists argue that merit-based achievement, or the perception thereof, is a necessary condition for tolerance of inequality (Huber \& Form, 1973; Kluegel \& Smith, 1986; Scitovsky, 1986); hence, this factor is a potentially important moderator of equality-efficiency trade-offs.

The compromise and value-guided trade-off orientations are likely to be meritocracy sensitive, whereas the maximin orientation is not predicted to be meritocracy dependent. Boulding (1962) argued that the compromise approach is premised on relative equity in a society. If the justification for inequalitynamely, rewarding hard work and achievement-is removed, support for efficiency should decline and emphasis on equality 
should increase. Similarly, utilitarians may relinquish their singular focus on efficiency when it becomes apparent that there is no reliable basis for predicting who will benefit from increased efficiency (in the low-meritocracy condition); under these conditions, it becomes difficult to defend why some should live in relative luxury while others are destitute. Likewise, egalitarians may find it difficult to argue for an equal distribution of wealth when there is a clear relationship between effort and achievement (in the high-meritocracy condition) and may increase their support for efficiency; under these conditions, the limits on upward mobility reside primarily in the person, not the society. Rawls (1971), on the other hand, posited that welfare of the lowest class will be foremost in individuals' minds regardless of the relationship between effort and social standing, thus implying no effects for meritocracy for those endorsing the maximin principle.

\section{Overview}

In three different studies, we varied the degree to which individual effort and ability determined economic standing (i.e., the meritocracy of the hypothetical society). In Study 1, different groups of subjects were given three different versions of the description of this society. They were informed that hard work was rewarded either $10 \%, 50 \%$, or $90 \%$ of the time. Subjects in each meritocracy condition made comparisons of the hypothetical income distributions shown in Table 1 . In this way we examined whether the three theories would be differentially applicable across meritocracy conditions.

In two additional studies we further tested the limiting conditions on trade-off strategies. Study 2 examined the possibility of a ceiling effect on concern for the upper class (i.e., the psychological point of "sufficient wealth" might have been passed by this upper class in the original set of income distributions, thereby diminishing concern about changes above this point). Alternatively, there could have been a concern about the excessive concentration of wealth in the top class. If either is the case, lowering the mean income for the top class should make concern for these families more acceptable and increase attention to the overall shape of the income distribution. That is, by reducing the wealth of the top income distribution, both the concentration of wealth in this class and the disparity of this class from others are lessened; thus, if either factor affected judgments, its effects would be mitigated in this study. Table 3 shows the distributions compared in Study 2 .

Study 3 makes societal background conditions highly salient through the use of a within-subjects design in which each subject is exposed to the full range of meritocracy manipulations. Continued use of a particular strategy across the three meritocracy conditions, as well as across the three studies, would be a forceful demonstration of the psychological power and generality of that specific trade-off strategy. Shifts in trade-offs as a function of situational conditions would illustrate the context dependence of people's notions of justice.

\section{Method}

Subjects were given information about a hypothetical society, Alpha, and other possible societies that could result if different governmental plans were implemented to restructure society. Societies, described in
Table 3

Income Distributions for Study 2

\begin{tabular}{crrr}
\hline $\begin{array}{l}\text { Income variability } \\
\text { (equality) } \\
\text { by quarter }\end{array}$ & Low & Medium & High \\
\cline { 2 - 4 } Low $^{\text {a }}$ & & & \\
1 & 13,000 & 16,000 & 19,000 \\
2 & 23,000 & 26,000 & 29,000 \\
3 & 35,000 & 38,000 & 41,000 \\
4 & 55,000 & 58,000 & 61,000 \\
Medium $^{\text {b }}$ & & & \\
1 & 9,000 & 12,000 & 15,000 \\
2 & 19,000 & 22,000 & 25,000 \\
3 & 39,000 & 42,000 & 45,000 \\
4 & 59,000 & 62,000 & 65,000 \\
High $^{\mathrm{c}}$ & & & \\
1 & 5,000 & 8,000 & 11,000 \\
2 & 15,000 & 18,000 & 21,000 \\
3 & 43,000 & 46,000 & 49,000 \\
4 & 63,000 & 66,000 & 69,000 \\
$M$ & 31,500 & 34,500 & 37,500 \\
\hline
\end{tabular}

Note. Numbers represent average income (in dollars) within a quarter.

${ }^{\text {a }} S D=18,065 . \quad{ }^{\text {b }} S D=22,174$. ' $S D=26,451$.

terms of average annual incomes per quarter for a family of four, were constructed from factorial combinations of overall mean income (prosperity) and income variability (equality). Subjects were presented with pairs of societies and were asked to state which of the two societies would be best for the people of Alpha.

\section{Study 1}

Instructions. Subjects read a description of a hypothetical society, Alpha, that included information about the existing income distribution in terms of mean income by quartiles and in U.S. dollar equivalents: $\$ 12,000, \$ 22,000, \$ 42,000$, and $\$ 82,000$. This income distribution is shown in the center panel of Table 1 . Subjects were told that the poverty line in Alpha was $\$ 10,000$, which would provide for basic needs of food, shelter, clothing, and health care, and that $10 \%$ of societal members were at or below this poverty line.

Subjects were also told about the level of meritocracy within the Alpha society. Meritocracy refers to the extent to which economic outcomes were determined by individual effort and ability. Factors external to individual effort and ability (e.g., connections in high places, inheritance) were either small, moderate, or large determinants of economic outcomes. The Appendix contains the instructions for the condition in which external factors played a small role in economic outcomes (the high-meritocracy condition).

Instructions stated that the government was considering ways to restructure the Alpha society. Half of the proposed plans emphasized equality, and half emphasized efficiency and prosperity. Subjects were informed that "econometric studies" had determined what effects these proposed policies would have on the income distribution. It was emphasized that there was no dispute over the effects of the possible plans (i.e., the various distributions would indeed lead to the predicted results) but that there was disagreement over which set of effects was more morally and politically desirable.

Subjects were asked to read descriptions of the proposed plans without imagining themselves to be a member of any particular class in this society. Proposed plans were described in terms of mean incomes for each quarter. These proposed plans are the remaining eight income 
distributions shown in Table 1. Subjects were presented with pairs of plans (and the original society) and voted for the one within each pair they believed to be best for Alpha.

Stimuli and procedure. Income distributions were constructed from a factorial design of income variability (operationalized in terms of income standard deviation) and average income for the entire society (operationalized in terms of average income). Income variability (equality) was low, medium, or high $(\$ 27,197, \$ 30,957$, or $\$ 34,924)$ Average income (efficiency) was also low, medium, or high $(\$ 35,500$, $\$ 39,500$, or $\$ 42,500$ ). Meritocracy in the societies was manipulated between subjects and was described in terms of the proportion of income accounted for by individual effort and ability. Meritocracy levels were low, medium, or high. That is, $10 \%, 50 \%$, or $90 \%$ of the income variance was determined by effort and ability.

Subjects first completed an Authoritarianism scale (from Altemeyer, 1981) and Political Orientation scales (from Costantini \& Craik, 1980; Rasinski, 1987) and answered questions concerning class, race or ethnicity, and sex. ${ }^{2}$ Subjects then were randomly assigned to one of three meritocracy conditions. They read the description of the hypothetical society and took a quick "knowledge test." Once they understood the task, they compared all nine distributions with each other. ${ }^{3}$ The order of income distribution pairs was counterbalanced across subjects using two Latin-square designs.

Following the comparisons, subjects completed a brief questionnaire about the importance of equality and efficiency in their judgments. Subjects allotted 100 points between equality and efficiency to reflect their relative concern for the two values during their comparisons. Finally, subjects completed the Rokeach Value Survey (Rokeach, 1973) ${ }^{4}$ After the experiment, the subjects were thoroughly debriefed.

Participants. Forty-six students from the University of California, Berkeley, and 23 students from Southern Illinois University at Edwardsville received credit in a lower division psychology course for their participation. They were run indivjdually in groups ranging from 2 to 10 people, with 23 subjects serving in each meritocracy condition.

\section{Study 2}

Study 2 was identical to Study 1 , with two exceptions. First, subjects completed a Protestant ethic scale (Mirels \& Garret, 1971, as adapted by Katz \& Hass, 1988) instead of the Authoritarianism scale used in Study 1 . Second, the mean incomes of the top quarter of all nine societies were reduced by $\$ 20,000$. Table 3 shows the nine income distributions used in Study 2. Forty-two students from the University of California received credit in a lower division psychology course for their participation, with 14 subjects serving in each meritocracy condition.

\section{Study 3}

Study 3 resembled Study 1 , except that meritocracy was manipulated using a within-subjects design and the Protestant ethic scale was substituted for the Authoritarianism scale. After completing the preliminary scales, subjects were exposed to three sets of societies. The societies varied only in terms of meritocracy. Income distributions were the same across all three sets of societies and were identical to those in Study 1 (see Table 1), but the percentage of income explained by individual effort and ability was $10 \%, 50 \%$, or $90 \%$. After reading the description for each level of meritocracy, subjects simply rank ordered the societies from best to worst for the people of the society. Thus, subjects were presented with all nine income distributions and ranked them from 1 (best) to 9 (worst). The order of presentation of meritocracy level was counterbalanced, as was the order of income distributions to be ranked. Thirty University of California undergraduates participated in Study 3.
Results

\section{Did Subjects Make Trade-Offs?}

For each subject, a ranking over income distributions was computed by counting the number of times that one distribution was preferred to the other income distributions. Scores could range from 0 to 8 . The higher the score, the greater the preference for that income distribution.

To investigate whether subjects made trade-offs, it was necessary to determine whether subjects had rankings consistent with lexicographic orderings. A lexicographic ordering over income distributions could occur as follows: All societies with high efficiency were ranked above those with medium efficiency, and all income distributions with medium efficiency were above those with low levels. A similar ordering could be determined for equality. All societies with high equality were ranked above those with medium equality, and all income distributions with medium equality were ranked higher than those with low levels. Lexicographic orderings for both equality and efficiency were examined. If subjects had rankings that were inconsistent with either of the two lexicographic orderings, then it was assumed that those subjects made trade-offs between measures of equality and efficiency.

In Study 1,75\% of the subjects had rankings that were inconsistent with the lexicographic orderings. In Study 2, wherein the average income in the highest quarter of all of the income distributions was reduced by $\$ 20,000,85 \%$ of the subjects had rankings that were inconsistent with the lexicographic orderings. In Study 3, wherein meritocracy was a within-subjects variable, $98 \%$ of the rankings were inconsistent with the lexicographic orderings. Thus, the majority of subjects in all three studies appeared to make trade-offs between equality and efficiency.

It could be argued that these percentages were misleadingly high because they did not allow any degree of error or inconsistency in applying the lexicographic rules. Therefore, subjects whose rankings were almost consistent with a lexicographic order were reclassified. Whenever a subject's ranking could be converted to a lexicographic order by reversing the rank orders of two adjacent ranks (e.g., 1 or 2,2 or 3), that subject was assigned to the lexicographic group. With this revised count,

\footnotetext{
${ }^{2}$ Subjects completed attitude and personality scales prior to the manipulation to avoid any effect of the manipulation on answers. An assessment was made that, given the content of these scales, the chances of a carryover from the manipulation to the scales were greater than vice versa.

${ }^{3}$ The "knowledge test" required subjects to state the (a) average income in the four quarters in Alpha, (b) poverty level, (c) percentage of societal members at or below the poverty line, (d) level of meritocracy, and (e) two factors of greatest concern to politicians of Alpha (equality and efficiency-prosperity). Finally, subjects were checked to make sure that they understood that the debate was over the social and moral desirability of the outcomes and not over the effects of proposed plans. All subjects passed the knowledge test.

${ }^{4}$ This scale was given last to avoid priming subjects' ratings of the relative importance of equality and prosperity before making paired comparisons because these values are included in the Rokeach Value Survey. That is, for this scale, the threat of carryover from the scale to the manipulation was deemed greater than vice versa.
} 
$62 \%, 67 \%$, and $89 \%$ of the rankings were inconsistent with a lexicographic order in Studies 1, 2, and 3, respectively. Even with this relaxed criterion, the majority of subjects appeared to make trade-offs between measures of equality and efficiency.

\section{Did the Maximin or Compromise Orientation Account for More Variance?}

Table 4 shows correlations among predicted rankings based on the compromise perspective, maximin perspective, and two versions of the value-guided perspectives: egalitarianism and utilitarianism. Note that the maximum theory is highly correlated with egalitarianism $(r=.84)$ and that the compromise theory is highly correlated with utilitarianism $(r=.86)$. These correlations were too high to permit tests that would decisively distinguish among orientations. Therefore, further tests were done between the maximin and compromise strategies, which were only slightly correlated $(r=.19)$. Versions of the valueguided approach were tested by examining correlations between political opinions and preferences for income distributions.

Individual rankings in each meritocracy condition were correlated with the predicted rankings for maximin and compromise orientations. In Study 1,83\%,70\%, and 65\% of the subjects had rankings that correlated more highly with the maximin approach than the compromise approach when meritocracy was low, medium, and high, respectively. In Study 2, $86 \%, 57 \%$, and $51 \%$ of the subjects had rankings that correlated significantly more highly with the maximin approach than the compromise approach when meritocracy was low, medium, and high, respectively, $\chi^{2}(2, N=42)=8.4 .^{5}$ Lowering the income of the top quarter in the income distributions by $\$ 20,000$ did not erode support for the maximin solution. Thus, in both Studies 1 and 2, the majority of subjects had rankings that were better described by the maximin principle than the compromise principle in the low-, medium-, and high-meritocracy conditions. However, the percentage of subjects best described by the maximin orientation tended to decrease as meritocracy increased. Moreover, support for the compromise orientation increased as that for maximin declined.

In Study 3, wherein meritocracy was a within-subjects variable, $77 \%, 63 \%$, and $27 \%$ of the subjects had rankings that correlated significantly more highly with the maximin strategy than the compromise strategy when meritocracy was low, medium, and high, respectively, $\chi^{2}(2, N=30)=6.64$. When meritocracy was low, the majority of individual rankings were better described by maximin; subjects' rankings correlated more highly with equality than efficiency. When meritocracy was high, the

Table 4

Correlations Among Rankings of Theories

\begin{tabular}{lcccc}
\hline \multicolumn{1}{c}{ Guided } & Compromise & Maximin & VGE & VGU \\
\hline Compromise & - & & & \\
Maximin & .64 &.- & & \\
VGE & .19 & .84 & - & \\
VGU & .86 & .53 & .00 & - \\
\hline
\end{tabular}

Note. $\quad$ VGE $=$ value-guided egalitarianism; $V G U=$ value-guided utilitarianism. majority of subjects had rankings that were better described by compromise; rankings correlated more highly with efficiency than equality. In short, as the salience of the relationship between effort and outcomes increased, subjects shifted from a maximin strategy to a compromise strategy that continued to set a safety net for income but that better rewarded effort.

\section{What Types of People Preferred the Maximin Versus Compromise Rule?}

Although our subject population was somewhat skewed toward the left on some measures (median scores of -10 on a -44 to 44 liberalism-conservative scale and -9 on a -18 to 18 egalitarianism-individualism scale), this was not so for all measures (median scores of 6 on a -66 to 66 Authoritarianism scale and 4 on 1 to 7 Democrat-Republican and liberal-conservative selfplacement scales). Attitudinal and personality measures were intercorrelated in predictable ways, decreasing the likelihood that correlates were biased by peculiarities of our subject population.

Correlations between membership in the maximin and compromise groups and personality, political, and demographic variables were performed to determine the characteristics of the two groups. The liberal-conservative scale correlated with group membership: Subjects whose rankings were better described by the maximin orientation tended to describe themselves as liberal $(r \mathrm{~s}=-.23$ and -.39 in Studies 1 and 2 , respectively). In addition, subjects whose rankings were better fit by maximin also tended to be Democrats $(r s=.18$ and .33 in Studies 1 and 2, respectively). These results are consistent with the value-guided approach, which predicts that one's political viewpoint should be related to voting preferences.

Subjects allocated 100 points to reflect the relative importance of equality and efficiency measures in their responses. Subjects who allocated more points to considerations of equality had income rankings that were better described by maximin than compromise ( $r=.31$ in Study 1$)$. In addition, two of the Protestant Ethic subscales-equality and need-correlated with group membership. Subjects who valued equality and had a strong desire to help the needy had income rankings that were better fit by maximin ( $r \mathrm{~s}=.26$ and .33 , respectively, in Study 2 ). Finally, subjects who predicted lower future incomes for themselves had rankings that were better described by the maximin principle $(r=.42)$. These results suggest that self-interest may lie behind individual preferences for income distributions. If people predict lower futures income for themselves, it is in their best interest to prefer societies that take better care of the poor.

\section{Did Individual Rankings Correlate With Social, Political, and Demographic Variables?}

Further analyses of individual subjects were done using the income rankings themselves rather than membership in the maximin and compromise groups. Multiple regression analyses were used to predict social, political, or demographic vari-

\footnotetext{
${ }^{5}$ Reported statistics are significant at the .05 level unless otherwise noted.
} 


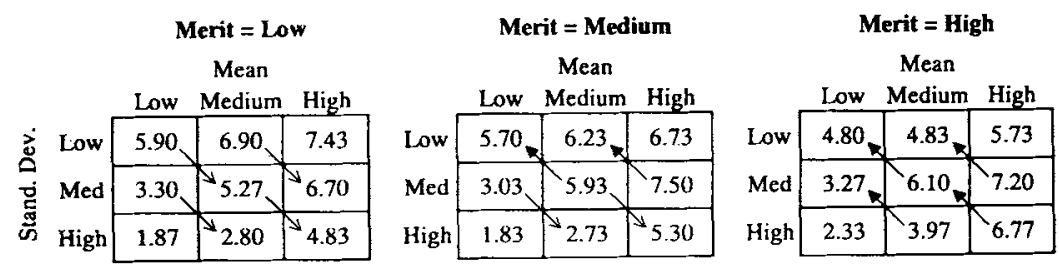

Figure 1. Mean societal rankings from Study 3 for each level of meritocracy (low, medium, and high). (1 = least fair and $9=$ most fair. Arrows show fairness trade-offs for pairs of societies that vary in equality and efficiency. Arrows point toward the society judged less fair. Downward arrows indicate that societies with greater equality are judged more fair than societies with greater efficiency. Upward arrows indicate that societies with greater efficiency are judged more fair than societies with greater equality. Standard Dev. $=$ standard deviation.)

ables from rankings of the nine income distributions. The majority of potential correlates were not related to income rankings. Income rankings failed to predict liberalism-conservatism self-report; liberalism-conservatism as determined by policy preferences; Democrat-Republican self-report; endorsement of egalitarianism or proportionalism; rankings of freedom, equality, and prosperity on the Rokeach Value Survey; level of political interest, understanding, and involvement; authoritarianism scores; sex; race or ethnicity; and geographic region of residency. Only income level and degree of valuation of self-respect on the Rokeach Value Survey were significantly related to rankings of income distributions. The more highly one valued self-respect, the less one preferred distributions placing the lowest class below the poverty line $\left(R^{2} s=.27\right.$ and .39 in Studies 1 and 2, respectively). The lower one's socioeconomic status, the more likely one favored high-equality income distributions $\left(R^{2}=.29\right.$ in Study 1). Those predicting a higher future income exhibited a greater preference for the original distribution and a greater aversion to the high-equality but lowand moderate-efficiency distributions $\left(R^{2}=.40\right.$ in Study 2$)$. These results suggest that even using the hypothetical society paradigm, it was not possible to eliminate self-interest effects completely.

In Study 3, the moderate-meritocracy condition produced the greatest political polarization of voting strategies. There were consistently powerful relationships between political ideology and voting over a range of measures in this condition: Those endorsing egalitarian attitudes were more likely to vote for high- and moderate-equality distributions than were those endorsing proportionality (equity and individualism) attitudes $\left(R^{2}=.63\right)$. Those labeling themselves conservative voted more often for high-efficiency distributions than did those who labeled themselves liberal $\left(R^{2}=.65\right)$, as was also the case for those labeling themselves Republican versus Democrat $\left(R^{2}=.66\right)$. Finally, those endorsing more conservative policies were more likely to vote for high-efficiency distributions, whereas those endorsing more liberal policies were more likely to vote for high-equality distributions $\left(R^{2}=.67\right)$. Comparatively, little ideological differentiation occurred in the low- and high-meritocracy conditions: There were no relations between individual attributes and voting preference in the low-meritocracy condition. There was only one significant relationship in the highmeritocracy condition, that between the Democrat-Republican self-placement and voting: Democrats voted less for highefficiency and low- to moderate-equality distributions than Republicans $\left(R^{2}=.50\right)$. No other measure of ideology was signif- icantly tied to a particular pattern of voting in the high-meritocracy condition.

\section{Summary}

With regard to Study 1 , the overwhelming majority of individuals used an egalitarian or Rawlsian approach, itself an "egalitarian" method in that improvement of the lot of the least fortunate is of first concern. This approach best captured the voting behavior of $73 \%$ of the subjects. Use of these strategies was reliably predicted from information about political ideology, a finding consistent with the value-guided perspective. Although the compromise principle performed less well than the maximin principle, both theories correctly predicted that distributions placing individuals below the poverty line would be least favored. Furthermore, support for the compromise principle increased as the level of meritocracy increased.

Study 2 demonstrated that support for the maximim strategy was not merely an artifact of the income distributions used in the voting comparisons, more specifically, that a ceiling effect on concern for the welfare of the upper class was not responsible for the support demonstrated for the maximum theory. Once again, the compromise orientation gained predictive power as meritocracy increased. This increase in support for compromise continued in Study 3 , in which subjects shifted from a maximin strategy that remained dominant in the lowand moderate-meritocracy conditions to a compromise between maximizing efficiency and ensuring that all were above the poverty line in the high-meritocracy condition. Finally, uncertainty about how to vote in the moderate-meritocracy condition was resolved along political lines, with more liberal subjects displaying a powerful preference for distributions of greater equality and more conservative subjects displaying a powerful preference for distributions of greater efficiency.

\section{Discussion}

Rawls's (1971) maximin principle of justice received impressive support at low and medium levels of meritocracy in the hypothetical studies. People adopted this societal decision rule to a greater extent than the compromise rule whenever they believed effort and rewards were only loosely related. When meritocracy increased in a within-subjects design, Boulding's (1962) compromise theory best predicted resolutions of the equality-efficiency trade-offs.

This support for maximin is in direct contrast to past experi- 
mental tests (Curtis, 1979; Frohlich et al., 1987) of Rawls's (1971) theory. One possible explanation of this difference is a failure in earlier studies to approximate adequately the "original position" as defined by Rawls: There is minimal similarity between deciding, from behind a veil of ignorance, how to structure a society that will determine one's future well-being and how to divide bonus resources in a brief experimental session. In our procedure, we did not attempt to simulate this original position (we believe that to be impossible-subjects cannot be made unaware of who they are); instead, we opted to see how subjects would distribute wealth in a society in which there were no obvious implications for subjects' material selfinterests. Under these conditions, the strategy of maximizing the welfare of the lowest class evinced itself.

It is important to note, moreover, that equality per se did not completely govern choice. The overwhelming majority of subjects made trade-offs between equality and efficiency. Indeed, subjects accepted greater inequality if the economic standing of all social classes was improved. Hence, a "qualified" egalitarianism such as Rawls's (1971) that does not favor equality purely for the sake of equality was predictive of individuals' behavior at low levels of meritocracy. In addition, both the maximin and compromise arguments predicted that distributions in which people fell below the poverty line would be least favored irrespective of the efficiency or inequality of these distributions, as they indeed were, and both orientations outperformed the value-guided orientation, which was neutral on the role of the poverty line in trade-offs. This point reinforces earlier findings that subjects have a deep aversion to allowing people to fall below the poverty line (e.g., Alves \& Rossi, 1978; Mellers, 1982), even if people at the bottom "deserve" it because they are not working hard. Any descriptive theory of justice must take this well-replicated fact into account.

All other things being equal, fulfillment of humanitarian (social welfare) concerns may be seen as being more imperative and legitimate than the rewarding of hard work and effort associated with equity and market principles. The precise nature of subjects' concern for the lowest class is, however, unclear. One possible explanation may reside in an "original fear" of falling into the lowest class, as Rawls (1971) posited, and relatedly in economic self-interest (note that subjects who predicted lower future incomes for themselves preferred the maximin principle). A second possible explanation is that subjects might have hoped to minimize the envy and hostility of the lowest class. A third possibility is that subjects anticipated that endorsement of humanitarian as opposed to utilitarian and market-based values would be more emotionally rewarding, a better purchaser of "moral satisfaction" (Kahneman \& Knetsch, in press). A fourth possibility is that subjects were concerned that some hard-working individuals had unjustly fallen into the lowest class (still a i0\% chance in even the most meritocratic society) and that concern might have motivated maximin preferences, a possibility testable in a hypothetical society in which effort and outcomes are perfectly correlated. Although we can only speculate about the possible answers here, understanding the motivational and functional underpinnings of humanitarian and egalitarian values should be a priority to justice researchers. As Greenberg and Cohen (1982) argued, "without knowing the reasons people have for their allocations, we cannot know whether we have learned anything about their understandings of, or their adherence to, norms of justice" (p. 456).

Support for Boulding's (1962) theory at high levels of meritocracy illustrates that people do not always place predominant concern on the welfare of the lowest class. When merit-based achievement is well established (and as it was made especially salient in a within-subjects design), rankings were better described by Boulding's compromise theory. Inequality becomes more acceptable as people are better rewarded for their efforts.

Support for the value-guided orientation also appeared in all three studies. In Studies 1 and 2, political opinions correlated with group membership in predictable ways. Republicans and self-identified conservatives tended to prefer income distributions in a manner better fit by the less egalitarian, compromise orientation. Those who valued equality and wanted to help the needy had income rankings better described by the maximin theory. These results suggest that political opinions correlate with preferences for various income distributions. In Study 3 , support for the value-guided perspective was predicated on situational ambiguity. Attitudinal and personality differences were generally overridden by the situational manipulations of meritocracy, equality, efficiency, and the poverty line, with the conspicuous exception of the moderate-meritocracy condition. Here, we found profound differences in distributive strategy according to political ideology in accordance with the valueguided orientation. Those on the left opted for equality; those on the right opted for efficiency. Moreover, the magnitude of the relationships between political ideology and distributive strategy was startlingly strong in the moderate-meritocracy condition, with measured individual differences in political viewpoint explaining between $50 \%$ and $67 \%$ of the total variation (far in excess of the regression results in other conditions and experiments reported here and far in excess of the usual predictive power for measures of ideology). When confronted with the meritocratic equivalent of the "glass half full or empty", liberals apparently focused on the empty portion (i.e., half of the time, the economic fates of people in the hypothetical society are determined by arbitrary and capricious forces outside of the individual's control) and conservatives on the full portion (i.e., half of the time, the economic fates of people faithfully reflect their talents and efforts to succeed). As a result, there was an unusually sharp ideological polarization of judgments. The bitter policy battles between liberals and conservatives in the real world spilled into the laboratory.

One possibility for future work is whether, although liberals and conservatives both support the ill-defined ideal of equality (McClosky \& Zaller, 1984), they disagree deeply over how exactly this idea should be interpreted and implemented (cf. Forgas, Morris, \& Furnham, 1982; Furnham, 1986; Heaven, 1990; lyengar, 1989; Lewis \& Furnham, 1986; Verba \& Orren, 1985). Liberals and conservatives may subscribe to differing lay theories about economic incentives and their impact on equality and efficiency, lay theories that, in turn, imply radically different political and economic policies. The exclusive focus here on predetermined outcomes might have obscured the impact of these ideologically grounded theories of how societies work. Our paradigm was well-equipped to examine the underlying values of liberals and conservatives but ill-equipped to examine the impact of conflicting causal theories on conceptions of justice. 
This ability to isolate value judgments is at once a strength and a weakness. It is difficult to obtain value judgments uncontaminated by real-world concerns. People rarely encounter situations in which they are told with certainty what the consequences of pursuing particular values will be. People also rarely make decisions in which they are completely insulated from the consequences of their choices. In everyday policy debates, liberals and conservatives may disagree because (a) they hold differing causal theories of economic growth, with liberals maintaining that little inequality is sufficient to motivate people to save, work hard, and exhibit entrepreneurial creativity and conservatives maintaining that large inequality is necessary to motivate the same (wealth-generation) behavior; (b) they harbor different interests and concerns, with liberals fearing that they may one day fall to the bottom of the economic pecking order and conservatives fearing that oppressive taxation will prevent them from enjoying the fruits of their labor; (c) they subscribe to different values, with liberals placing greater importance on equality than efficiency and with conservatives doing the opposite (see Tetlock \& Mitchell, in press). The current paradigm not only allows us to eliminate explanatory Alternatives (A) and (B), it allows us to specify when Alternative (C) possesses the greatest and weakest explanatory power (under conditions of moderate and low meritocracy, respectively). Surprising though it may sound, our research provides the most unambiguous experimental evidence to date that disagreements between liberals and conservatives are rooted not just in different assumptions about how to promote economic growth or in different conceptions of their self-interest but in fundamental values.

The internal validity strengths of the experiments reported here-their power to disentangle the influence of lay causal theories of economics from guiding values as well as to distance subjects from their self-interests-was, however, purchased at the price of reduced realism. Subjects were confronted by an admittedly artificial situation. Moreover, although we recruited subjects from two different locales who represented the gamut of political views, the data gathered still represent only the opinions of college students; the complexity of our experimental paradigm simply did not lend itself to survey research on representative samples. There is, however, no compelling reason to predict for other subject populations systematic divergences from the patterns of responding found here. The values of equality and efficiency are well represented throughout the American adult population, and research suggests that no single trade-off orientation predominates when middle-aged adults in the workforce confront "the big tradeoff" (see Hochschild, 1981; McClosky \& Zaller, 1984; Verba \& Orren, 1985).

Limitations notwithstanding, our research breaks new ground. It represents a systematic effort to explore how ordinary people reason through much-discussed conflicts between equality and efficiency at a societal level. The results reveal that although people often respond like Rawlsians, there are important individual-differences and situational qualifications. The more meritocratic the society, the more people shifted from the maximin decision rule to Boulding's (1962) compromise formula (especially in the within-subjects design). The more conservative the respondents, the more likely they were to act in accord with Boulding's theory (especially when there was maximum ambiguity about meritocracy). Taken together, these re- sults suggest that the research context can play a key role in priming competing conceptions of justice. In its strong form, this argument suggests that judgments of social justice have a cybernetic component that makes them responsive to shifting features of the social order and that ensures that no one position will be dominant for long (cf. March \& Olsen, 1989). If this is the case, one would expect predictable shifts in distributive strategies as different beliefs about justice and governance are primed. Indeed, given the proper conditions, it may well be possible to move the majority of people back and forth between highly egalitarian and highly individualistic conceptions of justice, although our findings as well as those of others suggest that the poverty line constrains the acceptability of inequality. Egalitarian norms may be activated by emphasizing procedural unfairness (e.g., discriminatory workings of the market; correlation of socioeconomic status with race, ethnicity, sex, religion), the role of chance and arbitrary factors in making people rich or poor, and the human suffering that occurs among the poor (i.e., the power of the emotionally charged label poverty line, the persuasive force of photographs and vivid stories that capture the plight of the poor). Norms of individualism, on the other hand, may be activated by highlighting the restrictions on personal economic freedom that redistribution and market regulation require, by emphasizing the degree of freedom and control people possess, and by invoking the imagery of free riders (welfare cheats) and chronic dependency on taxpayer-funded handouts.

From this perspective, inconsistency is not automatically evidence of hypocrisy. People simply have a hard time reconciling their conflicting concerns in a changing world. Justice is not a stable, well-defined ideal end-state toward which people purposefully move; rather, it is a dynamic, ever-shifting equilibrium between the excesses of too little regulation on the one hand and too much on the other. To paraphrase William Blake's Proverbs of Heaven and Hell, we never know we've had enough (equality or efficiency in this case) until we've had more than enough.

\section{References}

Abelson, R. P., \& Levi, A. (1985). Decision making and decision theory. In G. Lindzey \& E. Aronson (Eds.), The handbook of social psychology (pp. 231-310). New York: Random House.

Altemeyer, B. (1981). Right-wing authoritarianism. Winnipeg, Manitoba, Canada: University of Manitoba Press.

Alves, W. M., \& Rossi, P. H. (1978). Who should get what? Fairness judgments of the distribution of earnings. American Journal of Sociology, 84, 541-564.

Bauer, P. T. (1981). Equality, the Third World, and economic delusion Cambridge, MA: Harvard University Press.

Boulding, K. E. (1962). Social justice in social dynamics. In R. B. Brandt (Ed.), Social justice (pp. 73-92). Englewood Cliffs, NJ: Prentice Hall.

Bowie, N. E. (1971). Towards a new theory of distributive justice. Amherst: University of Massachusetts Press.

Brickman, P. (1977). Preference for inequality. Sociometry, 40, 303310.

Cook, T. D., \& Pearlman, B. (1981). The relationship of economic growth to inequality in the distribution of income. In M. J. Lerner \& S. C. Lerner (Eds.), The justice motive in social behavior. New York: Plenum Press.

Costantini, E., \& Craik, K. H. (1980). Personality and politicians: Cali- 
fornia party leaders, 1960-1976. Journal of Personality and Social Psychology, 38, 641-661.

Curtis, R. C. (1979). Effects of knowledge of self-interest and social relationship upon the use of equity, utilitarian, and Rawlsian principles of allocation. European Journal of Social Psychology, 9, 165175.

Dahrendorf, R. (1988). The modern social conflict. New York: Weidenfeld \& Nicolson.

Davis, K., \& Moore, W. E. (1945). Some principles of stratification. American Sociological Review, 10, 242-249.

Deutsch, M. (1989). Equality and economic efficiency: Is there a tradeoff? In N. Eisenberg, J., Reykowski, \& E. Staub (Eds.), Social and moral values (pp. 139-153). Hillsdale, NJ: Erlbaum.

Dworkin, R. M. (1980). Is wealth a value? Journal of Legal Studies, 9 , 191-225.

Einhorn, H. J., \& Hogarth, R. M. (1981). Behavioral decision theory: Processes of judgment and choice. Annual Review of Psychology, 32, 53-88.

Feagin, J. R. (1972, November). Poverty: We still believe that God helps those who help themselves. Psychology Today, pp. 101-129.

Feather, N. T. (1974). Explanations of poverty in Australian and American samples: The person, society, or fate? Australian Journal of Psychology, 26, 199-216.

Feather, N. T. (1985). Attitudes, values, and attributions: Explanations of unemployment. Journal of Personality and Social Psychology, 48, 876-889.

Festinger, L. (1957). Theory of cognitive dissonance. Evanston, IL: Row, Peterson.

Forgas, J. P., Morris, S. L., \& Furnham, A. (1982). Lay explanations for wealth: Attributions for economic success. Journal of Applied Social Psychology, 12, 381-397.

Friedman, M. (1962). Capitalism and freedom. Chicago: University of Chicago Press.

Frohlich, N., \& Oppenheimer, J. A. (1990). Choosing justice in experimental democracies with production. American Political Science Review, 84, 461-477.

Frohlich, N., Oppenheimer, J. A., \& Eavey, C. L. (1987). Choices of principles of distributive justice in experimental groups. American Journal of Political Science, 31, 606-636.

Furnham, A. (1986). Economic locus of control. Human Relations, 39 , $29-43$.

Greenberg, J., \& Cohen, R. L. (1982). Why justice? Normative and instrumental interpretations. In J. Greenberg \& R. L. Cohen (Eds.), Equity and justice in social behavior (pp. 437-469). San Diego, CA: Academic Press.

Heaven, P. C. L. (1990). Suggestions for reducing unemployment: A study of Protestant work ethic and economic locus of control beliefs. British Journal of Social Psychology, 29, 55-65.

Hochschild, J. L. (1981). What's fair? American beliefs about distributive justice. Cambridge, MA: Harvard University Press.

Hovenkamp, H. (1990a). The first great law and economics movement. Stanford Law Review, 42, 993-1058.

Hovenkamp, H. (1990b). Positivism in law \& economics. California Law Review, 78, 81 5-852.

Huber, J., \& Form, W. H. (1973). Income and ideology. New York: Free Press.

lyengar, S. (1989). How citizens think about national issues: A matter of responsibility. American Journal of Political Science, 33, 878-900.

Jasso, G., \& Rossi, P. H. (1977). Distributive justice and earned income. American Sociological Review, 42, 639-651.

Kahneman, D., \& Knetsch, J. L. (in press). Valuing public goods: The purchase of moral satisfaction. Journal of Environmental Economics and Management.

Katz, I., \& Hass, R. G. (1988). Racial ambivalence and American value conflict: Correlational and priming studies of dual cognitive structures. Journal of Personality and Social Psychology, 55, 893-905.

Kluegel, J. R., \& Smith, E. (1981). Beliefs about stratification. Annual Review of Sociology, 7, 29-56.

Kluegel, I., \& Smith, E. (1986). Beliefs about inequality: Americans' views of what is and what ought to be. New York: Aldine de Gruyter.

Kuttner, R. (1984). The economic illusion: False choices between prosperity and social justice. Boston: Houghton Mifflin.

Lewis, A., \& Furnham, A. (1986). Reducing unemployment: Lay beliefs about how to reduce current unemployment. Journal of Economic Psychology, 7, 75-85.

March, J. G., \& Olsen, J. (1989). Rediscovering institutions. New York: Free Press.

McClosky, H., \& Zaller, J. (1984). The American ethos. Cambridge, MA: Harvard University Press.

McConnell, C. R. (1987). Economics. New York: McGraw-Hill.

Mellers, B, A. (1982). Equity judgment: A revision of Aristotelian views. Journal of Experimental Psychology: General, 111, 242-270.

Mirels, H. L., \& Garret, J. B. (1971). The Protestant ethic as a personality variable. Journal of Consulting and Clinical Psychology, 36, 40-44.

Moore, B., Jr. (1978). Injustice: The social bases of obedience and revolt. White Plains, NY: M. E. Sharpe.

Okun, A. M. (1975). Equality and efficiency: The big tradeoff. Washington, DC: Brookings Institution.

Posner, R. A. (1977). Economic analysis of law. Boston: Little, Brown.

Posner, R. A. (1980). The value of wealth: A comment on Dworkin and Kronman. Journal of Legal Studies, 9, 243-252.

Rainwater, L. (1974). What money buys. New York: Basic Books.

Rasinski, K. A. (1987). What's fair is fair-Or is it? Value differences underlying public views about social justice. Journal of Personality and Social Psychology, 53, 201-211.

Rawls, J. (1971). A theory of justice. Cambridge, MA: Belknap Press.

Rohrbaugh, J., McClelland, G., \& Quinn, R. (1980). Measuring the relative importance of utilitarian and egalitarian values: A study of individual differences about fair distribution. Journal of Applied Psychology. 65, 34-49.

Rokeach, M. (1973). The nature of human values. New York: Free Press.

Schulz, U., \& May, T. (1989). The recording of social orientations with ranking and pair comparison procedures. European Journal of Social Psychology, 19, 41-59.

Scitovsky, T. (1986). Human desire and economic satisfaction: Essays on the frontiers of economics. Washington Square: New York University Press.

Slovic, P. (1975). Choice between equally-valued alternatives. Journal of Experimental Psychology: Human Perception and Performance, $l$, 280-287.

Sniderman, P., \& Tetlock, P. E. (1986). Public opinion and political ideology. In M. Herman (Ed.), Political psychology (pp. 62-96). San Francisco: Jossey-Bass.

Tetlock, P. E., \& McGuire, C. (1986). Cognitive perspectives on foreign policy. In R. White (Ed), Psychology and the prevention of nuclear war. New York: Free Press.

Tetlock, P. E., \& Mitchell, G. (in press). Liberal and conservative approaches to justice: Conflicting psychological portraits. In B. A. Mellers \& J. Baron (Eds.), Psychological perspectives on justice. Cambridge, England: Cambridge University Press.

Thurow, L. C. (1980). The zero-sum society: Distribution and the possibilities for economic change. New York: Basic Books.

Verba, S., \& Orren, G. (1985). Equality in America. Cambridge, MA: Harvard University Press. 


\section{Appendix}

\section{Hypothetical Society Instructions}

The following are the verbatim instructions given to subjects in the high-meritocracy condition.

\section{Ideal Societies Assessment Project}

Please read the paragraphs below and then go on to the next pages. If you have any questions during the experiment, please ask. It is important that you read all of the description below, understand what you have read, and keep the information in mind as you finish the questionnaire. You may refer back to the directions and description throughout the experiment while answering questions on later pages.

As you read the following paragraphs, imagine that you are an outside observer to the society described. Your task is not to imagine yourself as a member of any specific social class in Alpha; instead, we wish you to consider how societal conditions in Alpha are related to the whole range of social classes in Alpha. We are interested in your ideas about how society as a whole should be organized when your personal interests are not at stake.

\section{Society Alpha}

Alpha is a self-governed society. The people of Alpha come from a variety of racial and ethnic backgrounds. There is a broad variety of unskilled, technical, and professional jobs within Alpha. Average annual incomes for four-person families range from $\$ 12,000$ for the lowest $25 \%$ of the families, $\$ 22,000$ for the next $25 \%$ of the families, $\$ 42,000$ for the third $25 \%$ of the families, and $\$ 82,000$ for the top $25 \%$ of the families. The poverty line in Alpha is $\$ 10,000$, meaning that this amount of money will provide basic needs of food, shelter, clothing, and health services. Approximately $10 \%$ of four-person families in Alpha are at or below the poverty line.

Careful studies have shown that the income distribution in Alpha is overwhelmingly the result of individual effort and ability (i.e., individual effort and ability are excellent predictors of socioeconomic status in Alpha, determining $90 \%$ of financial outcomes). Those persons willing to work hard, take some risks, and invest time and effort to acquire skills that other people value have a very good chance of increasing their earning power (this applies to persons of all classes). Although it may take some time to rise from the poorest class to the wealthiest, and it may require "paying your dues" through tedious and time-consuming labor, anyone can achieve the top-paying jobs (and many have in fact done this). On the other hand, those persons unwilling to work hard rarely rise in the social system because incomes in Alpha are so dependent on individual effort investment. People must exert considerable effort just to stay in place and maintain their financial status; otherwise, harder working or more talented people from lower classes will take their places. In short, people in Alpha have an excellent chance of getting ahead when they work hard to do so. People are really only limited by how willing they are to work.

The government of Alpha is considering ways to restructure its society. Government officials are most concerned about how these changes will affect the level of equality and the standard of living in
Alpha, with certain politicians more concerned about income equality and others more concerned about prosperity, or the overall standard of living in Alpha. Consequently, no consensus has been reached, and the government is still debating what policies to pursue. Econometric studies have demonstrated (beyond reasonable doubt) the exact effects the various proposed policies would have on prosperity and equality in Alpha. Advocates of the different policies do not disagree over the factual issues (what consequences would follow from the different policies); they disagree over the moral and value issues at stake (which set of consequences-more prosperity or more equality-is more desirable).

We would now like you to compare income distributions (expressed in U.S. dollars) that would result from the government's proposed policies. We will give you the income distributions that would result from the various policies-according to the results of the econometric studies-and ask you to judge which distribution you would vote for if you were a member of the government of Alpha. As you make your choices, keep in mind the information about Alpha (e.g., about the poverty line and about the determinants of economic outcomes). In other words, given what you know about Alpha, we are going to ask you how you think the income distribution in AIpha should be restructured, if at all. You will be confronted with the same problems that members of Alpha's government are, namely, how to choose between these policies that emphasize equality and prosperity. You will have to decide what kind of income structure you think is best for Alpha as it is now.

There are eight new distributions, plus we would like you to consider the original distribution. That means you will be making 36 pairwise comparisons between all of the combinations of the distributions. Here is an example:

Say that Policy A produces the left income distribution and that Policy B produces the right income distribution. Policy A would restructure Alpha's income distribution so that the lowest class receives an average of $\$ 13,000$, the second class receives an average of $\$ 23,000$, and so on for the third and fourth classes. Policy B would restructure Alpha's income distribution so that the lowest class receives an average of $\$ 9,000$, the second class receives an average of $\$ 19,000$, and so on for the third and fourth classes. Your task will be to judge which income distribution is best for Alpha by voting for one of the distributions.

$\begin{array}{lcr} & \text { Policy A } & \text { Policy B } \\ \text { Lowest class } & 13,000 & 9,000 \\ \text { Second class } & 23,000 & 19,000 \\ \text { Third class } & 35,000 & 39,000 \\ \text { Fourth class } & 75,000 & 79,000\end{array}$

Given what you know about Alpha, which distribution would you vote for if you were a member of the government of Alpha? Circle your preference.

Received February 17, 1992

Revision received April 20, 1993

Accepted April 20, 1993 